\title{
Erratum to: Experimental investigation of some aspects of insect-like flapping flight aerodynamics for application to micro air vehicles
}

\author{
Salman A. Ansari • Nathan Phillips • \\ Graham Stabler • Peter C. Wilkins • \\ Rafał Żbikowski • Kevin Knowles
}

Published online: 26 February 2011

(C) Springer-Verlag 2011

\section{Erratum to: Exp Fluids (2009) 46:777-798 DOI 10.1007/s00348-009-0661-2}

In Ansari et al. (2009), we presented results of our lowReynolds number particle-image velocimetry (PIV) experiments on a wing rotating in a water tank. These experiments were aimed at investigating some aspects of insect-like flapping flight flow for application in micro air vehicle design.

Unfortunately, we have realised that our original paper suffered from erroneous calculations of experimental errors owing to confusion over the use of the terms 'spanwise' and 'chordwise'. Chordwise measurement planes are vertical planes, perpendicular to the wing span. Spanwise measurement planes are also vertical but lie along the wing span (perpendicular to the chordwise measurement planes). Together with the locally-level ground plane, the three planes form an orthogonal set. Figure 6 in Ansari et al.

The online version of the original article can be found under doi:10.1007/s00348-009-0661-2.

S. A. Ansari $(\square)$

Meggitt Avionics, 7 Whittle Avenue, Segensworth West,

Fareham PO15 5SH, UK

e-mail: salmansari@gmail.com

N. Phillips · G. Stabler $\cdot$ R. Żbikowski $\cdot$ K. Knowles Cranfield University, Defence Academy of the UK, Shrivenham, Swindon SN6 8LA, UK

P. C. Wilkins

Dstl Portsdown West, Fareham PO17 6AD, UK
(2009) shows 4 chordwise measurement planes and 1 spanwise measurement plane (see also Table 2 below).

We will now present the correct data, together with corrections to some other areas of confusion that we have noticed.

\section{Experimental error analysis}

Table 1 in Ansari et al. (2009) presented the PIV acquisition parameters for our experiments and Table 2 presented the test cases. These should have read as Tables 1 and 2 below.

In addition, the aspect ratio of our wings was 2.5 , not 4 as stated in Ansari et al. (2009, Sect. 3.1, last para). As a result of these correct data, our statement of experimental errors in Ansari et al. (2009, Sect. 4.2, last para) should have read as follows:

Thus, with an rms error of $0.43 \mathrm{px}$ for the spanwise measurements, this leads to a measurement uncertainty of $\pm 6.7 \times 10^{-4}$ and $\pm 0.039 \mathrm{~m} / \mathrm{s}$ for the $R e=500$ and 15,000 cases, respectively. Similarly, for the chordwise measurements, in the $R e=500$ and 15,000 cases an rms error of $0.35 \mathrm{px}$ leads to a measurement uncertainty of $\pm 8.2 \times 10^{-4}$ and $\pm 0.02 \mathrm{~m} / \mathrm{s}$, respectively.

\section{Presentation of results}

Several of the figures in Ansari et al. (2009) show PIV results for our wing from a section near the root out to beyond the tip; we did not state where this inboard section was. In fact Figs. 15, 16, 21 and 22 in Ansari et al. (2009) all show data starting at $10 \%$ of span. The titles of these figures, and Fig. 18, should not refer to Fig. 5. 
Table 1 PIV acquisition parameters

\begin{tabular}{|c|c|c|c|c|}
\hline & \multicolumn{2}{|c|}{ Chordwise measurements } & \multicolumn{2}{|c|}{ Spanwise measurements } \\
\hline & $R e=500$ & $R e=15,000$ & $\operatorname{Re}=500$ & $R e=15,000$ \\
\hline Area of interest $\left(\mathrm{mm}^{2}\right)$ & $70.5 \times 71$ & $70.5 \times 71$ & $109.6 \times 110.4$ & $109.6 \times 110.4$ \\
\hline Image size $\left(\mathrm{px}^{2}\right)$ & $1,008 \times 1,016$ & $1,008 \times 1,016$ & $1,008 \times 1,016$ & $1,008 \times 1,016$ \\
\hline Magnification & 0.129 & 0.129 & 0.083 & 0.083 \\
\hline Lens aperture (f\#) & 2.8 & 2.8 & 2.8 & 2.8 \\
\hline Calibration (px/mm) & 14.3 & 14.3 & 9.2 & 9.2 \\
\hline Pulse separation (ms) & 30 & 1.2 & 70 & 1.2 \\
\hline Observed maximum in-plane displacement (px) & $3-7.2$ & $5.1-10.6$ & $5.2-9.6$ & $3.7-7$ \\
\hline
\end{tabular}

Table 2 Test cases

\begin{tabular}{ll}
\hline $\begin{array}{l}\text { Chordwise measurement } \\
\text { planes }(\% \text { span) }\end{array}$ & $30,50,70,90$ \\
$\begin{array}{l}\text { Spanwise measurement planes } \\
(\% \text { chord })\end{array}$ & 50 \\
Azimuthal positions $\left(^{\circ}\right)$ & $5,10,15,30,45,60,75,90,135$, \\
& $180,225,270$ \\
Reynolds numbers & $500,15,000$ \\
\hline
\end{tabular}

Acknowledgments The authors acknowledge the partial support of the EPSRC through grant no. EP/C535278/1 (Stabler), the ORS
Award Scheme (Phillips) and the Cranfield University, Department of Aerospace, Power \& Sensors scholarships (Wilkins \& Phillips) for this work.

\section{Reference}

Ansari SA, Phillips N, Stabler G, Wilkins PC, Żbikowski R, Knowles $\mathrm{K}$ (2009) Experimental investigation of some aspects of insectlike flapping flight aerodynamics for application to micro air vehicles. Exp Fluids 46(5):777-798. doi:10.1007/s00348-0090661-2 